CAHIER DE RECHERCHE \#1604E

WORKING PAPER \#1604E

Département de science économique

Department of Economics

Faculté des sciences sociales

Université d'Ottawa

Faculty of Social Sciences

University of Ottawa

\title{
Survival of the Cleanest? Evidence from a Plant Level Analysis of Pollutant Emissions in Canadian Pulp and Paper Industry, 2005-2013*
}

\author{
J ean-Thomas Bernard ${ }^{\dagger}$, Md. J akir Hussain \\ and Mishaal Masud Sinha
}

May 2016

\footnotetext{
${ }^{*}$ We gratefully acknowledge the financial assistance provided by Social Sciences and Humanities Research Council of Canada (SSHRC). We thank the Forest Products Association of Canada (FPAC) for providing access to data on Canadian pulp and paper mills and also for the hospitality at their office. We would also like to thank the participants of Economics Empirical Lunch Seminar ( $1^{\text {st }}$ March, 2016) at the University of Ottawa for helpful comments and suggestions. We remain solely responsible for data preparation and for the views expressed in this paper.

${ }^{\dagger}$ Department of Economics, University of Ottawa, 120 University Private, Ottawa, Ontario, Canada, K1N 6N5; email: jbernar3@uOttawa.ca.
} 


\begin{abstract}
In this paper we capitalize on our access to plant level data in examining the relative changes in emissions of three major pollutants | Biochemical Oxygen Demand (BOD), Total Suspended Solids (TSS), and Greenhouse Gas (GHG) | for Canadian pulp and paper mills covering the period from 2005 to 2013. Over this eight-year period emissions of these three pollutants decreased by $31.0 \%, 35.5 \%$ and $42.5 \%$, respectively, for the plants included in our sample. Access to plant data allows us to investigate the roles played by some specific factors, such as changes in output, emission intensity, allocation of production among surviving plants, and plant closures, in contributing to the abrupt decline in emissions. Information on fairly homogeneous groups of plants, formed on the basis of production processes and output mixes, reveals a diverse picture of the roles played by these factors. For our analytical framework we adapt the factor decomposition technique proposed by Levinson (2015) to plant data. Our findings suggest that output change has been the main factor behind the reduction in emissions at the industry level, and that improvement of emission intensity by surviving plants | the so-called technique effect | brought a small, yet positive contribution. However, production shift among surviving plants and plant closure had almost no effects. Moreover, there are no indications that market operations determining plant output and plant survival led to lower emissions.
\end{abstract}

Key words: Biochemical Oxygen demand (BOD), Total Suspended Solids (TSS), Greenhouse Gas (GHG) Emissions, technique effect, pulp and paper industry.

JEL Classification: Q55.

\title{
Résumé
}

Dans ce texte, nous prenons avantage d'un accès à de l'information sur les usines pour analyser les changements d'émissions de trois polluants-demande biologique en oxygène (DBO), matières en suspension (MES) et gaz à effet de serre (GES)- provenant des usines canadiennes des pâtes et papiers de 2005 à 2013. Au cours de cette période, les émissions des trois polluants ont diminué de 31,1\%, 35,5\% et $42,5 \%$ respectivement pour les usines comprises dans notre échantillon. L'accès à l'information au niveau des usines nous permet d'étudier les rôles joués par des facteurs tels que la production, l'intensité des émissions, la répartition de la production entre les usines existantes et la fermeture d'usines, dans la baisse abrupte des émissions durant cette période. Les usines sont assignées à des groupes homogènes établis sur la base de leurs procédés de production et de la gamme de leurs produits. Nous adaptons la méthode de décomposition par facteurs proposée par Levinson (2015) pour prendre en compte la disponibilité d'information au niveau des usines. Nos résultats montrent que la chute de la production est le principal facteur associé à la baisse des émissions des trois polluants et que l'amélioration de l'intensité des émissions des usines encore en production en 2013 fut positive, mais faible. Par contre, la répartition de la production entre les usines et la fermeture d'usines ont eu très peu d'effet. L'évidence disponible ne montre pas que les opérations de marché qui déterminent le niveau de production de chaque usine ainsi que leur survie ont contribué à la baisse des émissions.

Mots clés : Demande biologique en oxygène(DBO), Matières en suspension(MES), Gaz à effet de serre (GES), Intensité des émissions, Industrie canadienne des pâtes et papiers.

Classification JEL : Q55. 


\section{Introduction}

A major policy concern in regulating pollution emitted by national manufacturing industries is how it may affect their competitive positions in world markets. Would the introduction of environmental regulations lead local factories to move to countries that apply less stringent regulations? This concern is particularly relevant with respect to greenhouse gas (GHG) emissions due to the global nature of its effects. In this case, plant relocation may bring little benefit with respect to climate change. Moreover, the local environmental improvements associated with this relative production shift do not reveal the extent of the worsening conditions that may occur elsewhere. ${ }^{1}$ Consequently, this issue has generated several studies that rely on factor decomposition techniques to identify the roles played by improvements in emission intensities at the industry level — the so-called technique effect, and by relative output shifts among industries. The technique effect indicates the extent to which factories have adjusted to environmental regulation by reducing emissions per unit of output relative to relocation. Furthermore, it is possible that such technical advances may be transferred to other countries, particularly the developing ones, and would generate additional environmental benefits.

In a recent study, Levinson (2015) analyses the emissions of six air pollutants by US manufacturing industries between 1990 and 2008. ${ }^{2}$ While previous studies relied on a residual estimate by subtracting the industry composition effect from changes in emission per unit of output, he provides a direct estimate of the technique effect for the set of industries under consideration. His results show that the decrease in pollution per dollar of shipments goes from $64 \%$ to $77 \%$ for the six pollutants he considered,

\footnotetext{
${ }^{1}$ Aldy (2016) presnets two frameworks, social welfare and political economy, in order to evaluate the competitive concerns realted to GHG emission mitigating policies.

${ }^{2}$ The six pollutants are Sulphur Dioxide $\left(\mathrm{SO}_{2}\right)$, Carbon Monoxide $(\mathrm{CO})$, Nitrogen Oxides $\left(\mathrm{NO}_{x}\right)$, particulates (PM 10), fine particles (PM 2.5), and Volatile Organic Compounds (VOCs).
} 
and that the technique effect provides the overwhelming share of that decline, ranging from $90 \%(95.0 \%)$ to $95.0 \%(102.0 \%)$ on the basis of Laspeyres (Paasche) indexes. ${ }^{3}$

Other studies similar to Levinson (2015) rely on aggregate measures of industry output, such as value added or value of shipments, and implicitly assume that all sources of output change, for example new plant entry, allocation of outputs among surviving plants, and plant retirement, have identical effects. The capacity of a plant to control pollution emissions at acceptable levels is a merit, and its output should be expected to grow relative to more polluting, or 'dirtier' plants when emissions are constrained by regulation. However, the costs associated with pollution emission control differ between plants, and are not directly observable. Furthermore, factors other than pollution emission, such as location and input prices, have significant effects on plant output and on its survival. It is, therefore, of particular interest to study the role that a plant's emission control capacity plays on its output level and also on its survival. However, such an analysis requires access to plant data. To the best of our knowledge, there are no studies dealing with industry pollutant emission intensities that has made use of plant level data. ${ }^{4}$

The objective of this paper is to conduct an analysis that measures explicitly the roles played by changes in total output, emission intensity, output allocation among surviving plants, and plant closure in the evolution of two water related pollutants Biochemical Oxygen Demand (BOD) and Total Suspended Solids (TSS) - in Canadian pulp and paper industry. In addition to these factors, energy efficiency and emission intensity of energy are also taken into consideration in the analysis of GHG emissions. In doing so, we take the advantage of access to mill level data for the Canadian pulp and paper industry covering the period from 2005 to 2013. Although the sample period is short, the significant downward spiral of this major Canadian industry during this time-span generates significant variations in factors that are of

\footnotetext{
${ }^{3}$ Except for VOCs, the indirect measures of technique shares are relatively smaller, but still fairly large, ranging from $88 \%$ to $93 \%$.

${ }^{4}$ Greenstone et al. (2012) use U.S. plant data to analyze the impact of environmental regulation on plant total factor productivity (TFP). We briefly disscuss their work in section 3 .
} 
particular interest. For our analytical technique we follow the factor decomposition framework proposed by Levinson (2015); however, we adapt the methodology to plant data.

We find that the BOD, TSS and GHG emissions from the mills included in our sample decreased by $31.0 \%, 35.3 \%$, and $42.5 \%$, respectively, over this short period of time. Contrary to the conclusion reached by Levinson (2015) and other studies making use of industry information only, we find output decrease to be the most important factor behind this reduction in emissions, while improvement in emission intensity by surviving mills, production shift among surviving mills, and mill retirement played minor roles. Our analysis of information on fairly homogeneous groups of mills, formed on the basis of their production processes and output mixes, shows more diverse results. Nevertheless, there is no indication that production allocation among surviving mills and mill retirement contributed to the reduction of emissions in a systematic way.

The order of presentation for the rest of the paper is as follows. Section 2 describes the evolution of Canadian pulp and paper industry over the sample period, and the regulations concerning the three pollutants considered in this study. Section 3 provides a brief review of relevant literature pertaining to the topic. Section 4 introduces the methodology — an adaptation of the factor decomposition technique proposed by Levinson (2015) to mill-level data. Section 5 offers an in-depth description of the data, while Section 6 presents and discusses the results. Finally, Section 7 offers some concluding remarks.

\section{Pulp and Paper Manufacturing in Canada}

This section provides some relevant information on the evolution and current state of Canadian pulp and paper industry along with a brief overview of the Canadian regulations related to BOD, TSS, and GHG emissions. In particular, we present information 
that was useful in organizing the data and in formulating the analytical framework presented in the next section.

\subsection{Pulp and Paper Making Technology}

The basics of paper making have remained relatively unchanged over the last century. Wood fiber is the main raw material and the first stage of production is to free wood fiber from raw wood to obtain pulp. There are two major forms of pulping processes that are most commonly used in this industry. In the first set, known as chemical processes, wood chips and sawdust are cooked in a cocktail of chemical products. Cellulose fibers are separated from wood by dissolving the lignin that binds fibers together. The fibers are then screened out of the mixture, and the remaining solution, known as black liquor, is burnt to produce heat (recovery boiler) and to recycle the chemical products that receive a caustic treatment. Another production cycle is then ready to be launched. In the second set of pulping process, known as mechanical processes, mechanical energy is used to grind round wood using abrasive materials, or to shred wood chips using narrow gap plates. Performance of this process can be enhanced by adding steam, pressure, and chemicals. At the second stage of production, cleansed fibers are mixed with additives and are spread on a rolling screen to be dried.

These operations yield various kinds of paper and cardboard products. Some mills produce only pulp, while others specialize in making paper with no pulping facilities. However, a large number of mills integrate pulping and paper making. There exists a world market for pulp products and also for some final products such as newsprint and printing paper. However, few other products such as tissue and cardboard are sold in nearby regional markets. Production of pulp and paper is highly energy and water intensive. It also generates a substantial amount of residues, some of which can be recycled while others require treatment before being released into the environment or shipped to landfills. 


\subsection{Current State of the Canadian Industry}

Vast forest lands yielding high quality wood fiber, rivers providing transport of logs to mills, low cost hydro power and water for industrial use, and readily available access to expanding foreign markets by railways and boats set the stage for the development of pulp and paper industry in Canada. A few mills were built in the late 19th century, however the industry expanded vastly in the 20th century up to the early nineties. ${ }^{5}$ According to the information provided by Forest Products Association of Canada (FPAC), there were 159 pulp and paper mills operating in Canada in $2005 .{ }^{6}$ Table 1 shows that the Canadian industry made double digit contribution to world production and export of wood pulp, paper and paperboard (export only), and newsprint. The latter has been the staple product of this Canadian industry. However, the number of mills still operating in 2013 dropped down to 84 - a $47 \%$ reduction over the eight year window. Both production and export for all of the categories reported in Table 1 experienced noticeable reduction between 2005 and 2013, and accordingly the Canadian industry lost significant grounds on world markets. Although the number of employees and Gross Domestic Product shares of pulp and paper in total Canadian manufacturing industries decreased from $4.7 \%$ and $5.3 \%$, respectively, in 2005 to $3.8 \%$ and $4.1 \%$ in 2013 , it is still a significant industry, particularly in light of its net contribution of $\$ 9.66$ billion to balance of payments in 2013 (Statistics Canada, 2016c,b; CFS, 2014).

\subsection{Emissions Regulations: BOD, TSS, and GHG}

The Fisheries Act provides the primary platform for federal regulations on water pollution in Canada. ${ }^{7}$ In accordance with the Fisheries Act, the Government of Canada enacted Pulp and Paper Effluent Regulations (PPER) first in $1971 .{ }^{8}$ The objective was

\footnotetext{
${ }^{5}$ Paillé (2012) describes the history of development of the Canadian industry since its inception.

${ }^{6}$ According to Hailu (2003), there were 162 pulp and paper mills in Canada in 1994.

${ }^{7}$ The summary presented here is based on Environment Canada (2012).

${ }^{8}$ Other industrialized countries introduced similar regulations over the same period.
} 
to control the discharges of harmful substances from pulp and paper mills in order to preserve water quality at a level suitable to fish, fish habitats and human consumption of fish. Any substance that could be acutely lethal to fisheries was prohibited. ${ }^{9}$ In particular, limits were imposed on the amounts of BOD substances and TSS released in rivers.

Initially only new mills had to comply with the requirements under PPER ${ }^{10}$ and thus little progress was made towards achieving the desired water quality. ${ }^{11}$ Subsequently, regulatory changes were introduced in 1992 to extend the application of PPER to all mills and to enforce effluent quality standards achievable through secondary wastewater treatment. In addition to producing effluents that are not acutely lethal to the Rainbow Trout, all mills have to perform environmental effect monitoring studies. In 2004, new regulations were ushered in to force mills to identify the causes of environmental effects linked to their effluents, and since 2008 they have had to come up with a plan to redress observed problems. These requirements give rise to mandatory monitoring studies. Moreover, some Canadian provinces enforce their own water quality regulations to be satisfied by the pulp and paper industry. However, the provincial standards cannot be less stringent than the federal ones. The current limit is set to $7.5 \mathrm{~kg} /$ ton for BOD and $11.25 \mathrm{~kg} /$ ton for TSS, and sampling takes place at the end of pipe.

The enforcement of water quality regulation led to a reduction of $97 \%$ and $90 \%$ in BOD and TSS discharges, respectively, during the period from 1970 to 2008. The pass rate of acute lethal tests increased from $25 \%$ in 1985 to $96.2 \%$ in 2013. Although nearly all mills are operating currently well below the BOD and TSS ceilings ${ }^{12}$, some failures concerning lethal toxicity to fish are still occurring. An environmental monitoring

\footnotetext{
${ }^{9}$ Environment and Climate Change Canada tests acute lethality by using Rainbow Trout - a common fish in Canadian rivers.

${ }^{10}$ In 1985 , only about $10 \%$ of the mills under operation were subject to the regulations (Environment and Climate Change Canada, 2016).

${ }^{11}$ See Sinclair (1991) for a detailed discussion on this. Also see Foulon et al. (2002) and Laplante and Rilstone (1996) for a discussion on monitoring and enforcement issues related to the Canadian pulp and paper industry.

${ }^{12}$ Over the sample period pass rates in BOD and TSS tests were above $99.7 \%$.
} 
study can be mandated if a difference between a treatment and a non-treatment area is observed. Hence the capacity of a mill to satisfy the BOD and TSS discharge standards should enter into the decision to expand or contract its output, or to close down.

Thus far the Government of Canada has not implemented binding regulations with respect to GHG emissions by the pulp and paper industry. However, some factors operating over the sample period contributed to the reduction of GHG emissions by the industry. First, in July 2008 the Government of British Columbia, home of the largest forest product industry in Canada, phased in a wide ranging carbon tax that reached $\$ 30$ per ton of $\mathrm{CO}_{2}$ e in July 2012. Second, the Government of Canada launched the Pulp and Paper Green Transformation Program in June 17, 2009. ${ }^{13}$ Under this program, chemical pulp and paper mills could acquire a credit of 16 cents per liter of black liquor produced between January 1 and May 4, 2009, and then use the earned credit to pay for approved projects that enhance environmental and economic performance. The cap under the program was $\$ 1$ billion and credits had to be used before March 31, 2012. Altogether 98 proposals ranging from $\$ 80,000$ to $\$ 100$ million were accepted, and accordingly, some 200 megawatts of renewable generating capacity were added through funding from this program. Finally, the average price of natural gas to industrial users plummeted from 31.99 cents/c.m. in 2005 to 12.50 in 2012, and to 14.92 in 2013 under the impetus of booming shale gas production in North America (Statistics Canada, 2016a). Such a substantial drop in price led mills to substitute natural gas for heavy fuel oil, and correspondingly to a reduction in GHG emissions.

In this paper we analyze the roles played by factors, such as total output, emission intensity of surviving plants, production allocation among surviving plants, and emission intensity of retired plants towards changes in BOD and TSS emissions during the recent shake-out of the Canadian pulp and paper industry. For GHG emissions,

\footnotetext{
${ }^{13}$ This is a response to a U.S. program. In 2008, the U.S. pulp producers found a tax loop-hole under the Alternative Fuels Mixture Tax Credit, that allowed them to receive tax credits of $\$ 0.50$ per gallon for the production of a mixture of black liquor and diesel. A total of $\$ 7.9$ billion is estimated to have been granted as subsidy before the end of the program on December 31st 2009.
} 
emission intensity of energy sources and energy efficiency are additionally taken into consideration.

\section{Literature Review}

Earlier studies dealing with the evolution of pollution emission relied on industry data to evaluate the factors responsible for changes in pollutant emissions. See Levinson (2015) for a list of related studies. Our study is the first to use plant level data for assessing these factors in analyzing the evolution of pollutant emissions in an industrial setting. To the best of our knowledge, there are no studies dealing with industry pollutant emission intensities that has made use of plant level data. ${ }^{14}$

In a recent work, Greenstone et al. (2012) analyze the effects of air quality regulation on US manufacturing total factor productivity (TFP) following the 1970 Clean Air Act Amendments that set minimum level that all US counties must satisfy for four pollutants: Carbon Monoxide (CO), Tropospheric Ozone $\left(\mathrm{O}_{3}\right)$, Sulphur Dioxide $\left(\mathrm{SO}_{2}\right)$, and Total Suspended Particulates (TSPs). On the basis of some 1.2 million observations on plants from the Annual Survey of Manufacturers (1972-1993), they estimate that large industrial emitters in non-attainment counties had on average $2.6 \%$ lower TFP. Moreover, they find that the use of deflated revenue as a measure of output rather than physical output and the closure of non-performing plant introduce significant underestimation biases that yield an estimated TFP decline of $4.8 \%$ over the same period. The pulp and paper industry is the only exception in the group of seven large industrial emitters, the TFP of its plants in non-attainment counties was $2.4 \%$ higher over the sample period.

Several recent studies have analyzed energy use and GHG emission at the industry level. One such study, CIEEDAC (2015), deals specifically with the Canadian pulp and

\footnotetext{
${ }^{14}$ Tang (2014) uses plant data to analyze Canada/U.S labor productivity differences over time. Plants of a particular industry are separated into two sets: small $(<500$ employees $)$ and large $(>500$ employees). Plant entries and exits are not taken into consideration.
} 
paper industry. It shows that energy intensity of output (terajoule/kiloton) increased from 24.9 in 2005 to 27.1 in 2013 and emission intensity of output (ton of CO2/ton) decreased from 0.245 to 0.219 over the same time period.

Adès et al. (2012) examine the evolution of GHG emission for the Québec pulp and paper industry from 1990 to $2006 .{ }^{15}$ Pulp and paper mills are classified on the basis of two pulping processes: chemical and mechanical. The authors estimate a multi-input (electricity, fossil fuels and wood residues) and multi-output (pulp, paper and board) translog function to represent the cost minimizing behavior of firms. Their results show that GHG emissions fell by more than $30 \%$ while output increased, and consequently GHG emission intensity dropped significantly. They find changes in output mix to be the main explanatory variable. Lower relative electricity price also played a role for the two groups of mills, however, biomass use and cogeneration are not significant explanatory variables.

In what follows, we present our methodology on the decomposition framework for analyzing the factors responsible for changes in the evolution of pollution emissions, followed by a brief description of our unique data set on Canadian pulp and paper mills, before finally, we present and discuss our results.

\section{Methodology}

The objective of this paper is to identify and assess the roles played by some specific factors that are responsible for changes in the evolution of pollution emission in an industrial setting. In doing so, we make explicit use of plant level data on Canadian pulp and paper mills that are aggregated into fairly homogeneous groups on the basis of pulping processes and types of output. For our analytical framework, in particular, we adapt the factor decomposition framework introduced by Levinson (2015) to incorporate the plant level dimension into the analysis. Changes in pollution emitted by a

\footnotetext{
${ }^{15}$ A total of 63 pulp and paper mills were operating in Québec during this period.
} 
set of industries are usually considered to originate from three sources: overall output level of the set of industries or the 'scale effect', relative output among industries or the 'composition effect', and emission intensity of each industry or the 'technique effect'.

Let us define:

$$
p_{i t}^{s}=V_{t}^{s} \cdot z_{i t}^{s} \cdot \theta_{i t}^{s},
$$

where $p_{i t}^{s}=$ emission of mill $i$ in group $s$ at time $t$,

$V_{t}^{s}=$ total output of group $s$ at time $t$

$z_{i t}^{s}=$ emission intensity of mill $i$ in group $s$ at time $t$,

$\theta_{i t}^{s}=$ output share of mill $i$ in group $s$ at time $t$,

$\sum_{i=1}^{n_{t}^{s}} \theta_{i t}^{s}=1$ and

$n_{t}^{s}=$ number of mills in group $s$ at time $t$.

Then total emission of mills belonging to group $s$ at time $t$ can be written as:

$$
P_{t}^{s}=\sum_{i=1}^{n_{t}^{s}} p_{i t}^{s}=V_{t}^{s} \cdot \sum_{i=1}^{n_{t}^{s}} z_{i t}^{s} \theta_{i t}^{s} .
$$

Now, emission in period $T$ relative to period 0 can be written in the following way:

$$
\frac{P_{T}^{s}}{P_{0}^{s}}=\underbrace{\frac{V_{T}^{s}}{V_{0}^{s}}}_{\text {(i) }} \cdot \underbrace{\frac{\sum_{i=1}^{n_{T}^{s}} z_{i T}^{s} \cdot \theta_{i T}^{s}}{\sum_{i=1}^{n_{T}^{s}} z_{i 0}^{s} \cdot \theta_{i T}^{s}}}_{\text {(ii) }} \cdot \underbrace{\frac{\sum_{i=1}^{n_{T}^{s}} z_{i 0}^{s} \cdot \theta_{i T}^{s}}{\sum_{i=1}^{n_{T}^{s}} z_{i 0}^{s} \cdot \bar{\theta}_{i 0}^{s}}}_{\text {(iii) }} \cdot \underbrace{\frac{\sum_{i=1}^{n_{T}^{s}} z_{i 0}^{s} \cdot \bar{\theta}_{i 0}^{s}}{\sum_{i=1}^{n_{0}^{s}} z_{i 0}^{s} \cdot \bar{\theta}_{i 0}^{s}}}_{\text {(iv) }},
$$

where $\bar{\theta}_{i 0}^{s}=\theta_{i 0}^{s} / \sum_{i=1}^{n_{T}^{s}} \theta_{i 0}^{s}, \sum_{i=1}^{n_{T}^{s}} \bar{\theta}_{i 0}^{s}=1$ and, $\left(n_{0}^{s}-n_{T}^{s}\right)$ represents the number of mills closed between period 0 and period $T$.

Equation (3) shows that the emissions at period $T$ relative to period 0 can be decomposed into the following four factors:

i. Total output of group $s$.

ii. The technique effect - it is a Paasche index of surviving mills' emission intensity during the two periods using their output share in the final period as weight. ${ }^{16}$

\footnotetext{
${ }^{16}$ Levinson (2015) labels this to be the direct estimate of the technique effect.
} 
iii. The composition effect - the shift of output shares among surviving mills. It is a Laspeyres index of surviving mills' output shares during the two periods using emission intensity in the initial period as weight.

iv. The mill closure effect — the numerator is the weighted average of emission intensity of surviving plants only in the initial period and the denominator is the weighted average of emission intensity of all the mills in the initial period. A ratio of less than 1 means that cleaner plants are surviving while a ratio above one indicates the converse.

In this paper, we apply the decomposition framework presented in equation (3) to BOD and TSS emissions. For GHG emissions, we include two additional factors into the analytical framework - GHG emission intensity of energy that depends on emission factors ${ }^{17}$ and energy mix, and energy efficiency of output. Accordingly, GHG emission of mill $i$ in group $s$ at time $t$ can be written in the following way:

$$
p_{i t}^{s}=V_{t}^{s} \cdot g_{i t}^{s} \cdot e_{i t}^{s} \cdot \theta_{i t}^{s}
$$

where $g_{i t}^{s}$ represents GHG emission per unit of energy of mill $i$ in group $s$ at time $t$ and $e_{i t}^{s}$ is the amount of energy use per unit of output for mill $i$ in group $s$ at time $t$.

Then GHG emission of group $s$ at period $T$ relative to period 0 can be decomposed into the following factors:

$$
\frac{P_{T}^{s}}{P_{0}^{s}}=\underbrace{\frac{V_{T}^{s}}{V_{0}^{s}}}_{\text {(i) }} \cdot \underbrace{\frac{\sum_{i=1}^{n_{T}^{s}} g_{i T}^{s} \cdot e_{i T}^{s} \cdot \theta_{i T}^{s}}{\sum_{i=1}^{n_{T}^{s}} g_{i 0}^{s} \cdot e_{i T}^{s} \cdot \theta_{i T}^{s}}}_{\text {(ii) }} \cdot \underbrace{\frac{\sum_{i=1}^{n_{T}^{s}} g_{i 0}^{s} \cdot e_{i T}^{s} \cdot \theta_{i T}^{s}}{\sum_{i=1}^{n_{T}^{s}} g_{i 0}^{s} \cdot e_{i 0}^{s} \cdot \theta_{i T}^{s}}}_{\text {(iii) }} \cdot \underbrace{\frac{\sum_{i=1}^{n_{T}^{s}} g_{i 0}^{s} \cdot e_{i 0}^{s} \cdot \theta_{i T}^{s}}{\sum_{i=1}^{n_{T}^{s}} g_{i 0}^{s} \cdot e_{i 0}^{s} \cdot \bar{\theta}_{i 0}^{s}}}_{\text {(iv) }} \cdot \underbrace{\frac{\sum_{i=1}^{n_{T}^{s}} g_{i 0}^{s} \cdot e_{i 0}^{s} \cdot \bar{\theta}_{i 0}^{s}}{\sum_{i=1}^{n_{0}^{s}} g_{i 0}^{s} \cdot e_{i 0}^{s} \cdot \theta_{i 0}^{s}}}_{\text {(v) }} .
$$

The five factors are:

i. Total output of group $s$.

\footnotetext{
${ }^{17}$ GHG emissions per unit of energy source are constant.
} 
ii. Emission intensity, given energy efficiency and output share of mills operating in the final period. It is a Paasche index of emission intensity per unit of energy during the two periods that uses as weight the product of energy efficiency and output share of mills in the final period. Since emissions factors are constant, this captures the effect of energy mix on GHG emissions.

iii. Energy efficiency per unit of output, given the emission intensity of mill $i$ in period 0 and the share of output of mill $i$ in period $T$. This presents the effect of energy intensity changes.

iv. The composition effect — the shift of relative outputs among surviving mills only during the two periods. This is a Laspeyres index that uses the product of emission intensity and energy efficiency of mills in the initial period as weight.

v. The mill closure effect - the numerator is the weighted average of emission intensity per unit of output for the surviving mills in period 0 , and the denominator is the weighted emission intensity per unit of output for all mills that were operating in period 0 . This ratio provides a comparison of the first period emission per unit of output of all surviving mills relative to all mills, including those that closed later on.

We consider that the capacity of a mill to reduce pollution emission is a positive asset. Thus our hypothesis is that the technique effect, the output shift among surviving mills, and mill closure should lead to lower emissions. However, the capacity of controlling emissions is only one of the variables that determined mill outputs during the downward spiral faced by the Canadian pulp and paper industry from 2005 to 2013. Mill data allows us to sort out the roles played by these factors in an empirical setting. 


\section{Data}

FPAC provided in-house access to pulp and paper mill information that it collects from surveys addressed to its members. Each mill that belongs to a member company is asked to provide annual data on purchased energy, energy and biomass use, pollutant emissions, and output-including cogeneration. Energy is reported in physical units and in joules. Released BOD and TSS, that are measured at pipe-ends, are reported in metric tons while GHG emissions are reported in metric tons of carbon dioxide equivalent $\left(\mathrm{CO}_{2} \mathrm{e}\right)$. Mill output includes products that are shipped out of mill premise, i.e. various types of pulp, paper and board. In the case of GHG, electricity sales (kWh) to local utilities are aggregated to mill physical output by using industrial electricity prices $(\$ / \mathrm{kWh})$ and appropriate output prices $(\$ /$ ton $)$ for each mill. ${ }^{18}$

According to FPAC, 159 mills were operating in Canada in 2005. However, the database includes only 107 mills as all mill owners are not FPAC members, and also because some members failed to answer the information request. Data are available for 77 mills out of the 84 mills that were under operation in 2013. There were few inconsistencies in the reported data, such as missing information for the base year 2005 or the final year 2013. However, a careful examination in distinguishing between mill closure and mill failure was conducted to report data in 2013. ${ }^{19}$ For BOD and TSS, our final sample includes 72 mills in 2005 and 53 were still operating in 2013. No new mills were built in this time frame. For GHG, the sample includes 80 mills in 2005 and 53 were still operating in 2013. There is no obvious reason why the missing information on some mills, particularly in 2005, should bias the analysis.

Mills exhibit differences in terms of pollution emissions that are directly related to pulping processes, integration level, and types of output. In order to arrive at fairly

\footnotetext{
${ }^{18}$ Since we do not know the electricity contract prices negotiated between mill owners and local utilities, we use the industrial electricity prices in each province obtained from the Hydro Québec website. FPAC provided the average annual prices of pulp, paper and board in Canada. Mill output mix is taken into consideration to form the aggregate of pulp, paper and board, and electricity sales. The operation of cogeneration facilities are not considered to be contributing to BOD and TSS emissions.

${ }^{19}$ Street address is used to check ownership or name change.
} 
homogenous groups, we adopted the mill classification developed by FPAC. ${ }^{20}$ The mill groups are as follows: ${ }^{21}$

Group 1 - Chemical market pulp (excluding de-inked/recycled pulp): This category includes all kraft - chemical market pulp mills (NAICS 322112)22 and excludes paper products from chemical pulp.

Group 2 - Papers from chemical or mechanical pulp: This group includes paper grades made from chemical pulp produced onsite, as well as coated groundwood specialties from mechanical pulp (NAICS 322121). It excludes paper from deinked/recycled pulp and newsprint.

Group 3 - Mechanical market pulp, newsprint, and uncoated ground-wood specialty grades and board grades from mechanical pulp: This category combines mechanical market pulp mills, newsprint and uncoated ground-wood grade mills, and a number of small specialty board manufacturers (NAICS 322111, 322122, 322130).

Group 4 - All grades from purchased fiber (recovered paper or purchased pulp): The category includes all product grades manufactured from purchased fiber (deinked/recycled pulp) (NAICS 322111, 322121, 322130).

To summarize, group 1 includes kraft chemical pulp mills only, while group 2 contains chemical pulp mills with paper making facilities, but does not include newsprint. Group 3 is comprised of mechanical pulp mills with related paper and board making facilities, and finally, group 4 consists of paper mills without wood pulp facilities.

\footnotetext{
${ }^{20} \mathrm{FPAC}$ uses this groupings to perform benchmarking studies for their members.

${ }^{21} \mathrm{FPAC}$ classification also includes a fifth group — board mills manufacturing from chemical pulp produced on site only (NAICS 322130). Since very few mills belong to this category and data are available for only one mill, this group is not included in our analysis.

${ }^{22}$ North American Industry Classification System (NAICS).
} 


\section{Results and Analysis}

In this section, we present and discuss the results obtained by applying the factor decomposition formula in (3) for BOD and TSS emissions, and in (5) for GHG emissions, to the data presented above.

\subsection{BOD Emissions}

Table 2 presents the results for BOD emissions. It can be seen that the BOD emissions from all four groups of mills decreased significantly between 2005 and 2013, and that the fall exceeded $50 \%$ for groups 2 and 3 . Output of all four groups declined as well. However, emission dropped more than output, expect for group 1.

BOD emission of group 1 decreased less than the fall in output mostly because of the production shift towards more polluting mills among the survivors, while emission intensity of surviving mills hardly improved at all and mill closure had little effect. BOD emission of group 2 decreased more than the decline in output, and the primary contributing factor was output shift towards cleaner mills while the emission intensity of surviving mills decreased by $3.8 \%$. However, less polluting mills were closed. In case of group 3, 11 out of 32 mills got retired between 2005 and 2013 due to the collapse of newsprint demand. BOD emissions fell more than output mostly due to retirement of mills that had higher emission intensities. Emission intensity improvement and production shift among surviving mills were minor factors. For group 4, BOD emission shows a deeper cut than output. However, the relevant factors are acting in the direction opposite to the case for group 3 - emission intensity and production shift among surviving plants brought a positive contribution, while much cleaner plants were closed.

In order to take into account the multiplicative form of factor decomposition, we use geometric weights to arrive at aggregates over the four groups of mills. Emission shares of each group in the initial period provide such weights. The application of 
this aggregation formula shows that BOD emission fell more than output following the modest contributions of emission intensity improvement and production shift among surviving mills, while mill closure played hardly any role.

\subsection{TSS Emissions}

Table 3 provides the results for TSS emissions. Our analysis on TSS emissions includes the same mills that were assessed for BOD emissions. TSS emissions of all four groups dropped significantly between 2005 and 2013, and the decline in emission exceeds the decrease in output, with the exception of group 3. TSS emission declined more than output for group 1 due to the significant reduction in emission intensity of surviving mills. However, production shift among surviving mills and mill closure had opposite effects. The large decline in TSS emissions for group 2 relative to the shrinking output is the result of positive contribution from all three factors, while the effects of emission intensity improvement of surviving mills is particularly significant. For group 3, TSS did not fall as much as output due to the production shift towards more polluting surviving mills. Finally, TSS decreased more than output for group 4 due to the outstanding reduction in emission intensity of surviving plants. However, less polluting plants got axed.

When we apply geometric weights based on TSS emission shares in 2005 to aggregate over the four groups, we observe that TSS fell more than output due to the marked improvement of emission intensity by surviving plants, while production shift among survivors and plant closure had smaller, but adverse effects.

\subsection{GHG Emissions}

Table 4 presents the results for GHG emissions along with the contributions of the five factors that we consider for analyzing the evolution of GHG emission over the period from 2005 to 2013 . The number of mills went down from 80 to 53, and mill closure was acute in group 1 (kraft chemical pulp mills) and in group 3 (mechanical pulping 
mills with newsprint, paper and board facilities). GHG emissions decreased less than output for group 1 and 2, while the converse occurred for group 3 and 4 .

For group 1, surviving mills shifted energy use towards sources that were more GHG intensive and also pushed backward energy efficiency. However, production moved to cleaner mills and dirtier mills were retired. For group 2, surviving mills used cleaner energy sources, while energy intensity deteriorated and cleaner mills were closed. Moreover, output shift among surviving plants played no significant role. In case of group 3 , there was a huge shift in favor of cleaner energy sources accompanied by closure of more polluting mills. However, energy efficiency and output shift among surviving mills had opposite, albeit smaller effects. GHG emission dropped more than output for group 4, and emission intensity of energy use and energy efficiency are the leading positive factors while production shift among surviving plants and mill closure have negative effects.

Weighted geometric totals of the four groups show that GHG emission fell more than output due to mill closure and improved emission intensity of energy use in surviving mills. However, energy efficiency slightly deteriorated while output shift among surviving plants had no effect.

If we consider the evolution of three pollutants discussed in this study - BOD, TSS, and GHG - for a particular group of mills, it can be observed that the relative contribution of each factor toward emission change, besides falling output, can be quite different. There is no clear indication that market operations underlying output shift among surviving mills and mill closure led to lower emissions.

When we consider the weighted total for the three pollutants, it can be seen that emission intensity per unit output of surviving plants decreased to 0.843 (TSS), 0.925 $(\mathrm{GHG})^{23}$ and 0.973 (BOD). Following Levinson (2015), this can be considered to be a direct estimate of the technique effect net of output shift among surviving mills and mill closure. The contribution of output shift among surviving mills towards

\footnotetext{
${ }^{23}$ The product of emission intensity of energy use and energy efficiency for GHG emission.
} 
lower emissions is positive (0.987) for BOD, almost nil (0.999) for GHG, and negative (1.070) for TSS. The contribution of mill closure is positive (0.930) for GHG, almost nil (1.002) for BOD and negative (1.021) for TSS. The technique effects are larger than the effects associated to production shift among surviving mills and mill closure.

\section{Conclusion}

Previous studies dealing with the evolution of pollution emission have relied on industry data to identify the role played by emission intensity improvement and output shift among industries. Output change at the industry level is the result of new mill opening, output expansion or contraction of existing mills and mill closure. All these sources are assumed to have the same effects on emission in studies relying on industry data. In this study, we use a unique set of data on Canadian pulp and paper mills from 2005 and 2013 to identify the role played by these factors on BOD, TSS and GHG emissions. Mills are classified into four groups to take into account production processes and output mixes. At the industry level, we find that output decrease was the primary factor contributing to lower emissions. Emission intensity improvements of surviving mills brought a positive contribution. However, our direct estimate of the technique effect is smaller than the estimate of Levinson (2015) even after taking into account the shorter time span of our sample. Among the six factors that we consider in this study, only production shift among surviving plants in case of TSS emission (1.070) and mill closure for GHG emission (0.930) turned out to be significant factors contributing to emission changes. The within-group analysis reveals a more diverse contribution of production shift among surviving mills and of mill closures. Nevertheless, there is no clear indication that these market operations, in this particular case, led to the survival of cleaner plants or to relative production shift in their favor. 


\section{References}

Adès, Julie, Jean-Thomas Bernard, and Patrick González, "Energy Use and GHG Emissions in the Quebec Pulp and Paper Industry, 1990-2006," Canadian Public Policy, 2012, 38 (1), 71-90.

Aldy, Joseph E., "Frameworks for Evaluating Policy Approaches to Address the Competitiveness Concerns of Mitigating Greenhouse Gas Emissions," Resources for the Future Discussion Paper 16-06, 2016. Available at SSRN: http://ssrn.com/ abstract=2738759 or http://dx.doi.org/10.2139/ssrn .2738759 .

CFS, "The State of Canada's Forests: Annual Report 2014," Canadian Forest Service, Natural Resources Canada. 2014. Retrieved on April 18, 2016: http://cfs.nrcan. gc.ca/pubwarehouse/pdfs/35713.pdf.

CIEEDAC, "Energy Use and Related Data: Canadian Paper Manufacturing Industries 1990 to 2013," Report Prepared by Canadian Industrial Energy Enduse Data and Analysis Centre, Simon Fraser University, Burnaby, BC, for the Forest Products Association of Canada (FPAC), 2015. Retrieved on January 12, 2016: http://www2.cieedac.sfu.ca/media/publications/Pulp_Paper_ Analysis_2014__2013__Final-2.pdf.

Environment and Climate Change Canada, "Canadian Environmental Sustainability Indicators: Managing Pulp and Paper Effluent Quality in Canada," Environment and Climate Change Canada, Ottawa, Ontario, 2016. Retrieved on March 20, 2016: http://ec.gc. ca/indicateurs-indicators/19374730-E0FE-47AA-B8E1-6C846B2CFA3E/ ManagingPulpandPaperEffluentQualityinCanada_en.pdf.

Environment Canada, "Status Report on the Pulp and Paper Effluent Regulations," Environment Canada, Ottawa, Ontario, 2012. Retrieved on January 10, 2016: 
https://ec.gc.ca/Publications/A231D61D-E897-4257-9E4B-F65CF5A8B5AD/ 780_PPER_Status_Report_e_04.pdf.

F.A.O., "Yearbook of Forest Products," Food and Agriculture Organization of the United Nations, Rome, 2007. Retrieved on January 10, 2016: http://www.fao. org/forestry/statistics/80570/en/.

_ , "Yearbook of Forest Products," Food and Agriculture Organization of the United Nations, Rome, 2014. Retrieved on January 10, 2016: http://www.fao.org/ forestry/statistics/80570/en/.

Foulon, Jérôme, Paul Lanoie, and Benoit Laplante, "Incentives for Pollution Control: Regulation or Information?," Journal of Environmental Economics and Management, 2002, 44 (1), 169-187.

Greenstone, Michael, John A List, and Chad Syverson, "The Effects of Environmental Regulation on the Competitiveness of US Manufacturing," NBER Working Paper, No. 18392, 2012. Retrieved on January 12, 2016: https://www.nber. org/papers/w18392.

Hailu, Atakelty, "Pollution Abatement and Productivity Performance of Regional Canadian Pulp and Paper Industries," Journal of Forest Economics, 2003, 9 (1), $5-25$.

Laplante, Benoit and Paul Rilstone, "Environmental Inspections and Emissions of the Pulp and Paper Industry in Quebec," Journal of Environmental Economics and Management, 1996, 31 (1), 19-36.

Levinson, Arik, "A Direct Estimate of the Technique Effect: Changes in the Pollution Intensity of US Manufacturing, 1990-2008," Journal of the Association of Environmental and Resource Economists, 2015, 2 (1), 43-56. 
Paillé, Gilbert, Histoire forestière du Canada, Les Publications du Québec, Québec, 2012.

Sinclair, William F, "Controlling Effluent Discharges from Canadian Pulp and Paper Manufacturers," Canadian Public Policy, 1991, 17 (1), 86-105.

Statistics Canada, "CANSIM Table 129-0003: Sales of natural gas, monthly," CANSIM (database). 2016. Retrieved on February 18, 2016: http://www5.statcan.gc . ca/cansim/a26?lang=eng\&id=1290003.

_, "CANSIM Table 379-0031: Gross Domestic Product (GDP) at Basic Prices, by North American Industry Classification System (NAICS), Monthly (dollars)," CANSIM (database). 2016. Retrieved on April 18, 2016: http://www5.statcan.gc.ca/ cansim/a26? lang=eng\&id $=3790031$.

_, "CANSIM Table 383-0031: Labour Statistics Consistent with the System of National Accounts (SNA), by Province and Territory, Job Category and North American Industry Classification System (NAICS), Annual," CANSIM (database). 2016. Retrieved on April 18, 2016: http://www5.statcan.gc.ca/cansim/a26?lang= eng\&id=3830031.

Tang, Jianmin, "Are Small or Large Producers Driving the Canada-US Labour Productivity Gap? Recent Evidence from Manufacturing," Canadian Journal of Economics, 2014, 47 (2), 517-539. 
Table 1: Canadian Pulp and Paper Production and Export In Thousand MT (\% World Share)

\begin{tabular}{ccccccccc}
\hline \multirow{2}{*}{ Year } & \multicolumn{2}{c}{ Wood Pulp } & & \multicolumn{2}{c}{ Paper and Paperboard } & & \multicolumn{2}{c}{ Newsprint } \\
\cline { 2 - 3 } & Production & Export & & Production & Export & & Production & Export \\
\hline \multirow{2}{*}{2005} & 25417 & 10612 & & 19613 & 15731 & & 7769 & 7324 \\
& $(14.6)$ & $(24.9)$ & & $(5.5)$ & $(13.9)$ & & $(20.3)$ & $(41.0)$ \\
& 17953 & 9822 & & 11133 & 8234 & & 3972 & 3658 \\
& $(10.3)$ & $(17.0)$ & & $(2.8)$ & $(7.5)$ & & $(13.5)$ & $(28.9)$ \\
\hline
\end{tabular}

Notes: F.A.O. (2007, 2014) 
Table 2: Results — BOD Emissions

\begin{tabular}{|c|c|c|c|c|c|c|c|}
\hline Group & Year & $\begin{array}{l}\text { No. of } \\
\text { Mills }\end{array}$ & $\begin{array}{l}\text { Total BOD } \\
\text { (metric tons) }\end{array}$ & $\begin{array}{l}\text { Total Output } \\
\text { (metric tons) }\end{array}$ & $\begin{array}{l}\text { Emission Intensity } \\
\text { of Surviving Mills }\end{array}$ & $\begin{array}{c}\text { Production Shift } \\
\text { Among Surviving Mills }\end{array}$ & Mill Closure \\
\hline \multirow[t]{3}{*}{1} & 2005 & 19 & 14,604 & $7,778,759$ & & & \\
\hline & 2013 & 15 & 13,001 & $6,464,541$ & & & \\
\hline & $(2013 / 2005)$ & & 0.890 & 0.831 & 0.989 & 1.073 & 1.009 \\
\hline \multirow[t]{3}{*}{2} & 2005 & 8 & 4,969 & $2,203,356$ & & & \\
\hline & 2013 & 7 & 2,282 & $1,154,388$ & & & \\
\hline & $(2013 / 2005)$ & & 0.459 & 0.524 & 0.962 & 0.841 & 1.083 \\
\hline \multirow[t]{3}{*}{3} & 2005 & 32 & 8,763 & $10,180,824$ & & & \\
\hline & 2013 & 21 & 4,057 & $5,613,694$ & & & \\
\hline & $(2013 / 2005)$ & & 0.463 & 0.551 & 1.010 & 1.034 & 0.803 \\
\hline \multirow[t]{3}{*}{4} & 2005 & 13 & 5,352 & $1,006,999$ & & & \\
\hline & 2013 & 10 & 3,898 & 748,474 & & & \\
\hline & $(2013 / 2005)$ & & 0.729 & 0.743 & 0.886 & 0.842 & 1.313 \\
\hline Weighted Total* & & & 0.659 & 0.686 & 0.973 & 0.987 & 1.002 \\
\hline
\end{tabular}

Notes: *Geometric weighted total using group emission shares in 2005 as weights. 
Table 3: Results — TSS Emissions

\begin{tabular}{|c|c|c|c|c|c|c|c|}
\hline Group & Year & $\begin{array}{l}\text { No. of } \\
\text { Mills }\end{array}$ & $\begin{array}{c}\text { Total TSS } \\
\text { (metric tons) }\end{array}$ & $\begin{array}{l}\text { Total Output } \\
\text { (metric tons) }\end{array}$ & $\begin{array}{l}\text { Emission Intensity } \\
\text { of Surviving Mills }\end{array}$ & $\begin{array}{c}\text { Production Shift } \\
\text { Among Surviving Mills }\end{array}$ & Mill Closure \\
\hline \multirow[t]{3}{*}{1} & 2005 & 19 & 25,487 & $7,778,759$ & & & \\
\hline & 2013 & 15 & 20,818 & $6,464,541$ & & & \\
\hline & $(2013 / 2005)$ & & 0.817 & 0.831 & 0.875 & 1.078 & 1.043 \\
\hline \multirow[t]{3}{*}{2} & 2005 & 8 & 7,656 & $2,203,356$ & & & \\
\hline & 2013 & 7 & 2,423 & $1,154,388$ & & & \\
\hline & $(2013 / 2005)$ & & 0.317 & 0.524 & 0.694 & 0.894 & 0.974 \\
\hline \multirow[t]{3}{*}{3} & 2005 & 32 & 20,454 & $10,180,824$ & & & \\
\hline & 2013 & 21 & 12,315 & $5,613,694$ & & & \\
\hline & $(2013 / 2005)$ & & 0.602 & 0.551 & 0.972 & 1.157 & 0.971 \\
\hline \multirow[t]{3}{*}{4} & 2005 & 13 & 3,798 & $1,006,999$ & & & \\
\hline & 2013 & 10 & 1,558 & 748,474 & & & \\
\hline & $(2013 / 2005)$ & & 0.410 & 0.743 & 0.449 & 0.961 & 1.279 \\
\hline Weighted Total* & & & 0.617 & 0.670 & 0.843 & 1.070 & 1.021 \\
\hline
\end{tabular}

Notes: *Geometric weighted total using group emission shares in 2005 as weights. 
Table 4: Results - GHG Emissions

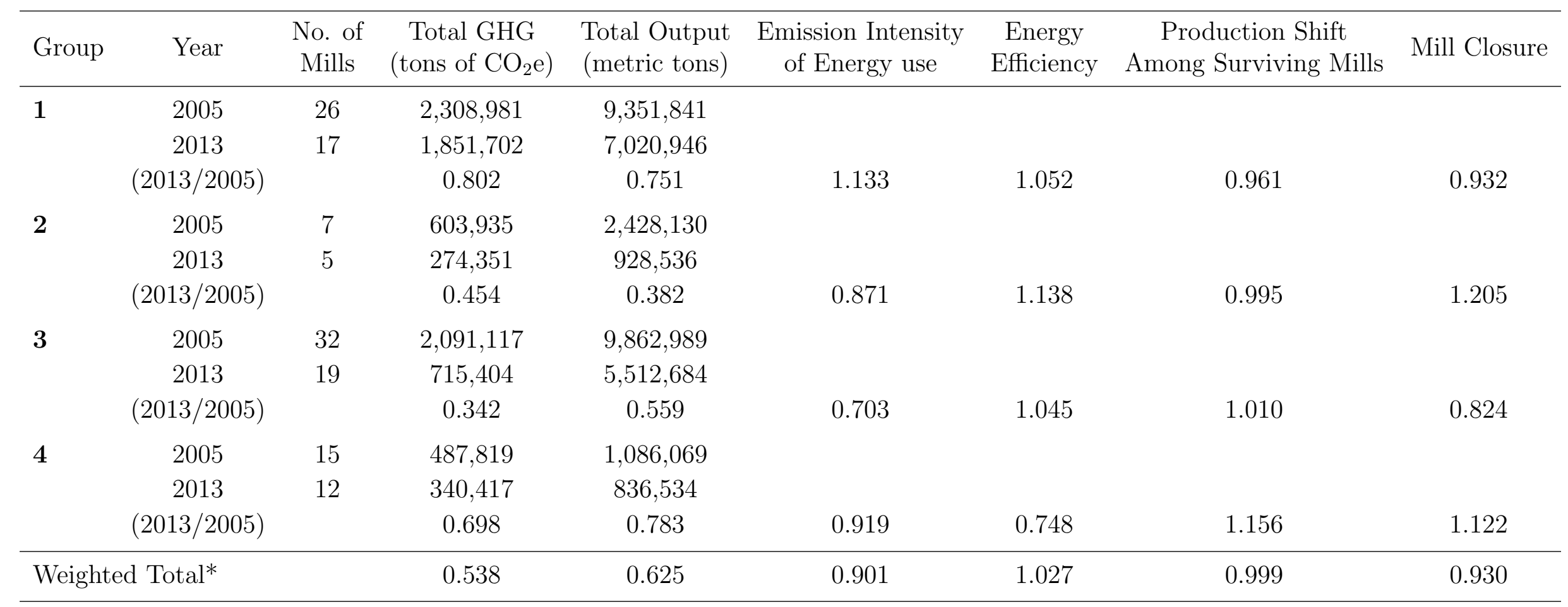

Notes: *Geometric weighted total using group emission shares in 2005 as weights. 